\title{
AUDITORIA E CONTROLE INTERNO NO SETOR PÚBLICO E SUA CONTRIBUIÇÃO PARA A DEMOCRACIA
}

\author{
Lethícia Dutra Leal Ferreira FERNANDES ${ }^{1}$
}

Talilian Joelma BORGES ${ }^{2}$

Maurício Cezar Resende LEITE JUNIOR ${ }^{3}$

\begin{abstract}
1Bacharel em Administração (UNISUL), email: lethicia_leal@ hotmail.com.
${ }^{2}$ Contadora e Professora da Universidade do Vale do Rio Verde (UninCor), Pós Graduada em MBA em Gestão Empresarial e Inteligência de Negócios, email: talilianborges@yahoo.com.br.

${ }^{3}$ Doutor em Recursos Hídricos em Sistemas Agrícolas, Professor Tempo Integral da Universidade do Vale do Rio Verde (UninCor), email: mauricio_cezar_leite@yahoo.com.br.
\end{abstract}

\section{Recebido em: 05/02/2017 - Aprovado em: 12/05/2017 - Disponibilizado em: 01/07/2017}

\section{RESUMO:}

Esse trabalho de conclusão de curso tem como objetivo analisar a influência da auditoria e do controle interno da administração pública sobre o exercício da democracia. Abordam-se a evolução da Gestão Pública e a influência da auditoria e do controle interno no monitoramento das contas públicas, na elaboração de políticas públicas que realmente atendam a demanda da sociedade e na aplicabilidade da Lei de Transparência de forma que estimule uma democracia participativa. Também são levantadas as dificuldades encontradas no acesso da sociedade civil ao controle social. A auditoria e o controle interno, juntamente com a transparência e a accountability, são a base não só para o controle do erário público, garantindo a sobrevivência econômica do país, mas também para qualquer participação do cidadãocliente na administração pública.

Palavras-chave: Auditoria e Controle Interno; Democracia participativa; Transparência e Accountability; Controle Social na Administração Pública.

\section{AUDIT AND INTERNAL CONTROL IN THE PUBLIC SECTOR AND ITS CONTRIBUTION TO DEMOCRACY}

\begin{abstract}
:
This course conclusion work aims to analyze the influence of audit and internal control of public administration on the exercise of democracy. Address the evolution of the Public Management and the influence of auditing and internal control on the monitoring of public accounts, on the elaboration of public policies that actually meet the demands of society and on the applicability of the Transparency Law in a way that stimulates a democracy participatory approach. The difficulties in the access of civil society to social control are also raised. Audit and internal control, together with transparency and accountability, are the basis not only for the control of the public purse, guaranteeing the economic survival of the country, but also for any participation of the citizen-client in the public administration.

Keywords: Auditing and Intern Control; Participatory democracy; Transparency and Accountability; Social control in public administration.
\end{abstract}




\section{INTRODUÇÃO}

Depois de passar pelos modelos do Patrimonialismo e da Burocracia, vivemos hoje o momento da implantação do modelo Gerencial na Administração Pública. Esse novo modelo de gestão impõe como meta a eficiência e eficácia nos seus atos, onde o cidadão é identificado como consumidor dos serviços prestados pelo Estado, e como tal, todos os atos no setor público devem ser tomados tendo em vista a satisfação de seu "cidadão-cliente". A transparência dos atos públicos é vital para o aferimento da qualidade dos mesmos, portanto, é mister o trabalho da controladoria e auditoria interna na prestação de contas ao cidadão.

A Constituição Federal vigente impõe o controle interno como uma atribuição à Administração Pública em vista do volume do erário advindo principalmente da arrecadação de impostos cobrados, e deve se prestar contas da gestão desses recursos aos contribuintes, observando os princípios da economicidade, legalidade e eficiência, entre tantos outros, prevista na Carta Magna.

O intuito desse artigo é assinalar a ligação entre a evolução da gestão pública com a transparência dos atos administrativos e o fortalecimento da democracia, e qual o papel da controladoria e auditoria interna nesse cenário. O desenvolvimento do texto está esquematizado em cinco etapas: expor brevemente a história da Administração
Pública e a Nova Gestão Pública; elucidar o conceito de accontability, controle social e sua relação com a democracia; descrever as atribuições da auditoria interna e da controladoria interna, suas diferenças e qual relação entre elas, não obstante apontar qual o impacto de suas ações na democracia; e levantar as dificuldades do setor público na prestação de contas de forma clara e de fácil entendimento ao cidadão, assinalando os pontos de melhoria nesse processo. Na última etapa temos as considerações finais.

\section{MATERIAL E MÉTODOS}

\subsection{Problema de Pesquisa}

A Administração Pública tem buscado aproximar-se dos métodos da iniciativa privada, assim, buscando eficiência e eficácia dos seus atos. O conceito de "ouvir e servir o cliente" também vem sido batido no âmbito público, uma vez introduzido o conceito de gestão por resultados e de cliente-cidadão.

Assim sendo, formulou-se o seguinte problema:

Qual o impacto da controladoria e auditoria interna dos atos administrativos no controle social?

O tema é de grande relevância, pois apesar da implementação de práticas privadas no setor público estar ocorrendo desde a década de 90, e da quantidade de leis que vêm 
normatizando o assunto desde então, no meio acadêmico ainda não é um tema tão abordado, embora seu grande potencial de estudo.

\subsection{Metodologia}

A metodologia utilizada foi a pesquisa bibliográfica, com a consulta a livros da área de gestão pública, controle e auditoria por autores nacionalmente renomados. Também houve o estudo das legislação brasileira, artigos, teses e dissertações publicadas relevantes ao tema, e na internet em links de órgãos do governo e artigos on line relacionados com o assunto.

"Qualquer que seja o campo a ser pesquisado, sempre será necessária uma pesquisa bibliográfica, para se ter um conhecimento prévio do estágio em que se encontra o assunto" (DOMINGOS FILHO; SANTOS, 2002, p. 12).

A pesquisa bibliografia é o núcleo que qualquer tipo de estudo. É essencial para a produção de material intelectual, e no caso do tema abordado nesse artigo, ela é não só essencial como suficiente, pela quantidade de leis que permeiam e normatizam o assunto.

Primeiramente foi realizada uma leitura prévia, a fim de conseguir o levantamento de obras e publicações que fossem pertinentes ao tema estudado. Uma vez o levantamento feito, sobre os textos selecionados foi executada uma leitura seletiva para distinguir qual obra, ou qual parte da obra seria relevante para um estudo mais profundo.

Após essa etapa, foi feita uma leitura crítica com o objetivo de analisar as informações significativas, ordená-las, foi formalizado um fichamento, contendo a organização e resumo do material analisado. E por último, com o objetivo da produção desse artigo, foi realizada a leitura interpretativa, relacionando o conteúdo das fontes consultadas com os argumentos fundamentados.

\section{RESULTADOS E DISCUSSÃO}

\subsection{A história da Administração Pública e a Nova Gestão Pública}

Após a II Guerra Mundial, viu-se a necessidade do Estado assumir um papel assistencialista, sendo o principal investidor e o responsável pelo desenvolvimento econômico e social. Assim, aquisições e gastos públicos cresceram extraordinariamente, e apesar de ter um sucesso inicial, a máquina publica chegou a um ponto de inchaço que comprometeu a sua eficiência.

Ocorreu também o aparelhamento do Estado à burocracia Werberiana, com objetivo de combater o nepotismo e clientelismo gerado pela cultura de administração patrimonal no Brasil, herança dos tempos do 
Império. Apesar dos benefícios da Burocracia, o Estado se tornou ainda maior, e a administração pública ainda mais lenta.

Nas décadas de 80 e 90 ocorreram as primeiras reformas administrativas no mundo. A Nova Zelândia, ao definir o "fiscal responsibility act" definiu critérios de transparência e responsabilidade na administração das finanças públicas, e a medida passou a ser considerada uma referência no debate internacional sobre política fiscal (GIAMBIAGI; ALEM, 2011). Inglaterra, Austrália e Estados Unidos, também fizeram profundas reformas no estado, e importaram práticas da administração privada para o setor público, com vistas ao aumento da produtividade e eficiência.

A ideia de planejamento estratégico tem origem no meio militar, e foi abordada pela administração pública no Brasil pela primeira vez no período do Regime Militar com o Decreto-Lei 200/67. Apesar da introdução dos conceitos de planejamento e controle, com a dificuldade da crise internacional e a instabilidade de um governo não democrático, pouco se mudou na prática da administração do Estado (KANAANE at all, 2010).

Inflação acima do desejado, alto déficit público, crescente ineficiência e alto custo da manutenção da máquina pública, agravando o comprometimento da imagem do
Brasil no cenário macroeconômico. Era necessária uma reforma no aparelho do Estado.

O Brasil iniciou sua "Reforma da Gestão Pública" durante o governo de Fernando Henrique Cardoso, com o Plano Diretor da Reforma do Aparelho do Estado brasileiro, que trouxe conceitos e ferramentas da administração privada para a administração pública, como o planejamento estratégico, a descentralização, a delegação de competências, e a focalização no Core Business - parte central e principal da atuação da organização. Essa nova que visão procura alinhar a gestão pública com a economia mundial globalizada, e trazer saúde financeira ao Estado para ele ser capaz de atender as demandas sociais através das políticas públicas. Bresser-Pereira, um dos mentores da primeira reforma do Estado pontuou:

\footnotetext{
A essência da reforma seria a mudança de estratégia no planejamento e na gestão. No modelo weberiano, prioriza-se o controle dos processos, partindo-se do valor primordial de prevenção da corrupção. No modelo gerencial, priorizam-se desempenho e resultado, que podem ser controlados a posteriori, sem abrir mão da legalidade durante os processos, partindo-se da primazia do valor da eficiência. Metas, indicadores de desempenho e resultados são previamente planejados e depois controlados ao longo dos processos, por meio de cronogramas físico-financeiros, como já praticava a burocracia weberiana. A diferença é a ênfase no controle dos processos como fins em si mesmo. (BRESSERPEREIRA, 2008 apud KANAANE; FIEL FILHO; FERREIRA, 2010, p. 51-52)
} 


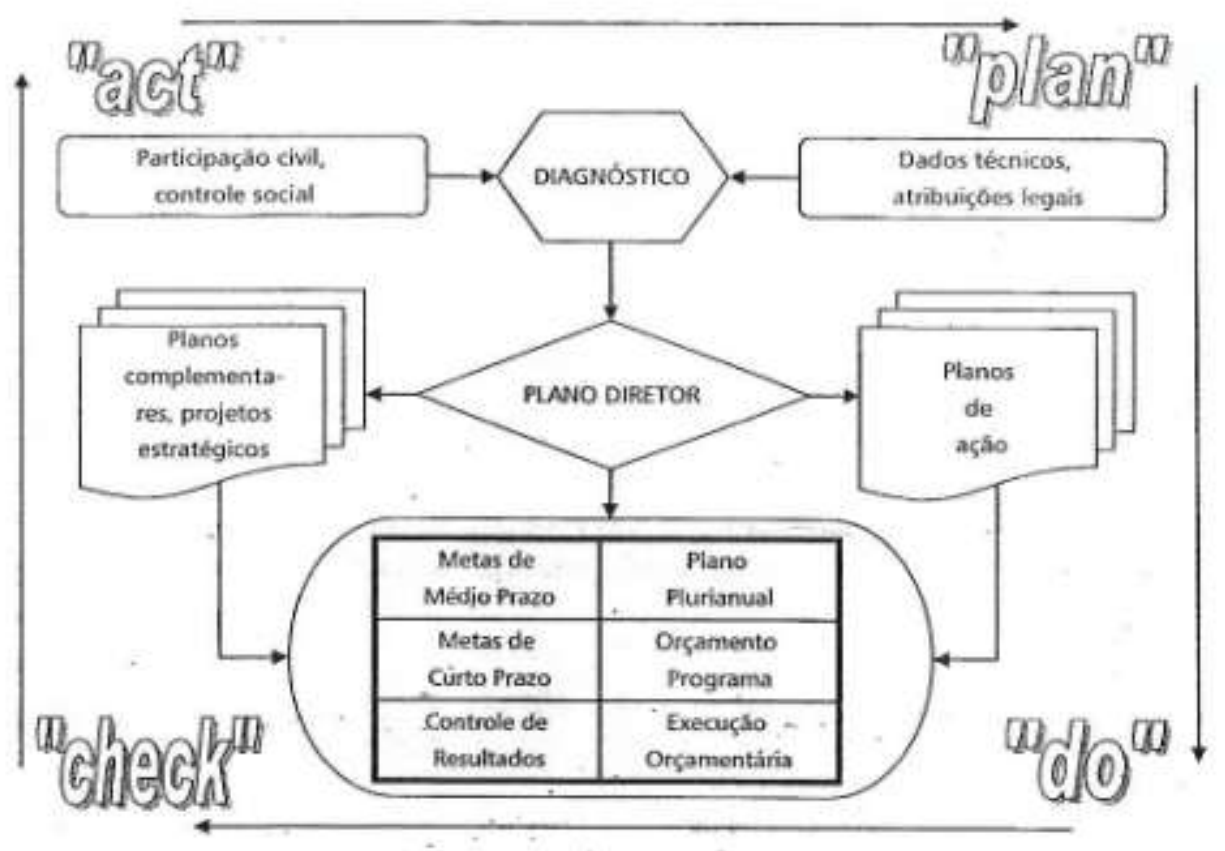

Figura 1 - Plano Diretor antes do Estatuto da Cidade.

Fonte: (KANAANE at all, 2010, p. 59)

Em 2000, a Lei Complementar 101, conhecida como Lei de Responsabilidade Fiscal, é promulgada com as diretrizes de que o Estado deveria realizar não mais um planejamento orçamentário como o previsto anteriormente pela burocracia Werberiana, mas deve lançar mão de um planejamento estratégico, com estabelecimento de diretrizes, metas e planos.

Art. $1^{\circ}$ Esta Lei Complementar estabelece normas de finanças públicas voltadas para a responsabilidade na gestão fiscal, com amparo no Capítulo II do Título VI da Constituição. $\S 1^{\circ} \mathrm{A}$ responsabilidade na gestão fiscal pressupõe a ação planejada e transparente, em que se previnem riscos e corrigem desvios capazes de afetar o equilíbrio das contas públicas, mediante o cumprimento de metas de resultados entre receitas e despesas [...] (LCP 101, 2000)

Boris Fausto (2013), numa avaliação isenta sobre o governo FHC, aponta um mérito que cabe ressaltar: “[...] a estabilização da economia brasileira, depois de mais de uma década de inflação, alta, crônica e crescente, processo que implicou a reordenação das finanças públicas, da qual a Lei de Responsabilidade Fiscal é a expressão mais visível e abrangente."

Outros três conceitos importados do setor privado que são fundamentais a esse estudo são os de transparência, accontability e cliente-cidadão, os quais serão abordados no próximo tópico.

É fundamental fixar qual o papel esperado da nova gestão pública: um governo pautado em ações eficientes, feitas de forma transparente, exercendo sua obrigação na prestação de contas, e atingindo os resultados estabelecidos no planejamento estratégico inicial. 


\subsection{Accontabillity, Controle Social e}

\section{Democracia}

A Governança Pública é a aplicação da governança corporativa do setor privado ao setor público, que prima pela interação horizontal entre atores estatais e não estatais durante a construção das políticas publicas. Entre esses atores estão os stakeholders, que são, segundo Orchis (2001), “[...] grupos de interesse que se relacionam, afetam e são afetados pela organização e suas atividades." (apud KANAANE at all, 2010).

Accontability é o termo que sintetiza a responsabilidade pela prestação de contas de uma organização aos seus stakeholders, que no caso do serviço público tem como representantes: os servidores, os fornecedores, o governo e o cliente-cidadão. $\mathrm{O}$ clientecidadão é o contribuinte, o consumidor real ou potencial dos serviços públicos ofertados direta ou indiretamente pelo estado. E esse termo, nos traz o juízo que o cidadão deve ser visto pelo setor público da mesma forma que o cliente é visto pelo setor privado: como a razão de existir da organização (KANAANE at all, 2010).

A democracia é fortalecida quando o cidadão recebe essa prestação de contas por parte dos agentes públicos, pois a informação gera posicionamento, que e é o primeiro passo para a participação do povo nas decisões publicas. Portanto, a Accontability fomenta o controle social do povo sobre as ações do
Estado. A transparência na prestação de contas por parte do Estado para o clientecidadão, assegurando a integridade dos atos, corrigindo os desvios, garantindo o cumprimento do bem-comum.

A desburocratização da máquina pública passa pela implementação dessa visão de que o serviço público não deve ser somente eficiente, ou seja, ser feito de forma correta, mas também deve ser eficaz, atingindo os resultados propostos e as metas traçadas. Esses indicadores de eficiência e eficácia são a base das avaliações, como podemos observar:

\footnotetext{
Os indicadores de eficácia mostram a relação entre alcance de metas e tempo ou, em outras palavras, o grau em que se alcançam os objetivos e metas do programa, em um determinado período.

Os indicadores de eficiência mostram a relação entre custo e benefícios, buscando a minimização do custo total ou a maximização do produto para um gasto total previamente fixado. (KANAANE et all, 2010, p. 7-8)
}

A administração pública vai evoluindo para uma cultura de fazer o certo de maneira certa, de responsabilidade com o atendimento das necessidades dos cidadãos, que não são nada mais que os clientes - e financiadores das ações públicas. O agente público deve trabalhar com empenho, pois o Estado não deve apenas "sobreviver", mas assim como uma empresa, deve trabalhar para oferecer qualidade no serviço oferecido ao seu consumidor.

Existe uma crescente adesão dos órgãos públicos aos modelos de excelência 
gerencial no Brasil, criando mecanismo de fiscalização, controle e avaliação da execução dos orçamentos, do desempenho dos servidores e dos resultados atingidos pelo órgão em conformidade ao que foi planejado previamente. Será abordado no próximo tópico dois desses mecanismos: a auditoria e o controle interno.

\subsection{Controle Interno}

O controle é uma das cinco funções universais da Administração, que são: Prever, Organizar, Comandar, Coordenar e Controlar. É instrumento essencial para atingir os objetivos propostos no planejamento estratégico, pois é ele quem dá o feedback para as ações corretivas.

Ele se relaciona com todas as funções, e, de acordo com o art. 13 do DL 200/67, deve ocorrer em todos os níveis e em todos os órgãos da administração pública federal:

[...] deverá exercer-se em todos os níveis e em todos os órgãos, compreendendo, particularmente:

a) o contrôle, pela chefia competente, da execução dos programas e da observância das normas que governam a atividade específica do órgão controlado;

b) o contrôle, pelos órgãos próprios de cada sistema, da observância das normas gerais que regulam o exercício das atividades auxiliares;

c) o contrôle da aplicação dos dinheiros públicos e da guarda dos bens da União pelos órgãos próprios do sistema de contabilidade e auditoria. (DL 200, 1967)

Mendes pontua que "o controle interno pode ser entendido como todas as ações e medidas adotadas numa entidade, destinada a prevenir e salvaguardar o patrimônio daquela, bem como acompanhar os processos e rotinas ali existentes.” (MENDES at all, 2011).

Aprofundando mais o tema, sobre o Controle Interno, Scatolino e Trindade (2015) conceituam que "É aquele que cada um dos Poderes exerce sobre seus próprios atos. É exercido dentro de um mesmo poder". E o parágrafo único do artigo 70 da Constituição Federal, afirma que "Prestará contas qualquer pessoa física ou jurídica, pública ou privada, que utilize, arrecade, guarde, gerencie ou administre bens e valores públicos ou pelos quais a União responda, ou que, em nome desta, assuma obrigações de natureza pecuniária" (CF, 1988).

Scatolino e Trindade (2015) ainda relatam que no caput do artigo 70 da $\mathrm{CF} / 88$, são estabelecidos quatro parâmetros de controle: a Legalidade, que é a característica de conformidade das ações com as leis e com a Constituição; a Legitimidade, que é o mérito das decisões tomadas em conformidade com o interesse público; as Finanças, que são a contabilidade, a aplicação de subvenções, as despesas e a renúncia de receitas; e por último a Economicidade, que é a compatibilidade de custo-benefício da ação.

Somente estabelecimento de metas não é suficiente para garantir uma boa gestão. Deste modo, o controle interno, quando estabelece um parâmetro de controle e verifica se ele está sendo seguido, auxilia a 
administração a constatar se os objetivos estão sendo alcançados, mensurando o grau de eficiência e eficácia dos atos administrativos. Ele possibilita uma correção de rumos na hora certa e do jeito certo, otimizando a produtividade.

Ele ocorre dentro do próprio órgão, entidade ou setor, descobre e corrige os erros para que não seja necessária a intervenção e sanção do erro pelo controle externo. De acordo com José Hernandes Perez (1998, p. 67), “os controles internos tem como objetivos a obtenção de informação adequada, estimulação do respeito e da obediência às políticas da administração, proteção dos ativos e promoção da eficiência e eficácia operacional" (apud MICHEL, [2014?]).

A contabilidade é ferramenta essencial na etapa do controle, principalmente $\mathrm{o}$ operacional, pois ela dá condições de prover ao controle interno os registros dos fatos de forma apurada, eficiente e correta. Juntamente com o controle interno, a contabilidade auxiliará diretamente na auditoria interna.

$$
\text { Giacomoni (2010) ressalta que o }
$$
controle interno vem evoluindo, e que são os dispositivos legais, principalmente a LRF que reforçam a prática do controle dentro da Administração Pública:

Ao contrario do que ocorria no passado, quando a ênfase do controle interno residia, exclusivamente, nas questões ligadas ao cumprimento dos aspectos legais do gasto publico, os novos dispositivos trazem positivas inovações no campo do controle substantivo. E exatamente o caso da disposição que estabelece como uma das finalidades do controle a avaliação dos resultados das gestões orçamentária, financeira e patrimonial, segundo os conceitos de eficiência e eficácia.

$[\ldots]$

A Lei de Responsabilidade Fiscal trouxe novidades ao fixar as competências do organismo responsável pelo controle interno. Numa das mais Importantes, o responsável firmara, juntamente com a autoridade financeira e eventualmente outras definidas em ato próprio de cada Poder, o Relatório de Gestão Fiscal emitido pelos titulares de Poder e de órgãos dotados de autonomia, como o Ministério Publico e Tribunais de Contas. (GIACOMONI, 2010, p. 344)

\subsection{Auditoria Interna}

Sobre a relação entre auditoria interna e controle interno, é um equivoco pensar que auditoria é o mesmo que controle. A auditoria faz parte do controle, porém se posiciona no topo da pirâmide dele. Ela avalia, supervisiona e fiscaliza o nível de credibilidade dos controles internos, de modo geral, se sobrepondo às atividades operacionais (ALVES; REIS, 2005).

Michel (2014) complementa dizendo que "a auditoria, seja ela governamental ou particular, tem por finalidade a atividade de fiscalização dos atos praticados na área orçamentária, financeira e patrimonial, e se refere à etapa final do controle interno."

A auditoria interna é contínua e trabalha para atestar a "saúde" da organização, emitindo juízo sobre o funcionamento do controle interno dela. Observa o todo, proporcionando uma visão geral do cenário ao examinar e avaliar suas atividades. A finalidade mais importante da 
auditoria interna é auxiliar na tomada de decisão a partir do parecer emitido de forma clara e objetiva. A auditoria previne tanto a fraude - ato intencional, quanto o erro - ato não intencional. (NBT T 11, 1997)

O parecer do auditor, ou seja, a emissão da sua opinião é a alma da auditoria. Mesmo o auditor interno estando integrado à organização, ele não deve ser subordinado às pessoas cujo trabalho examina para não comprometer o seu parecer, e deve prestar informações somente aos gestores que o incumbiram da função. Assim, cabe ressaltar que a figura do auditor deve ser uma pessoa independente, mas com capacidade técnica e profissional para emitir esse parecer com confiabilidade.

A Auditoria Interna se posiciona da seguinte forma na estrutura organizacional (Figura 2):

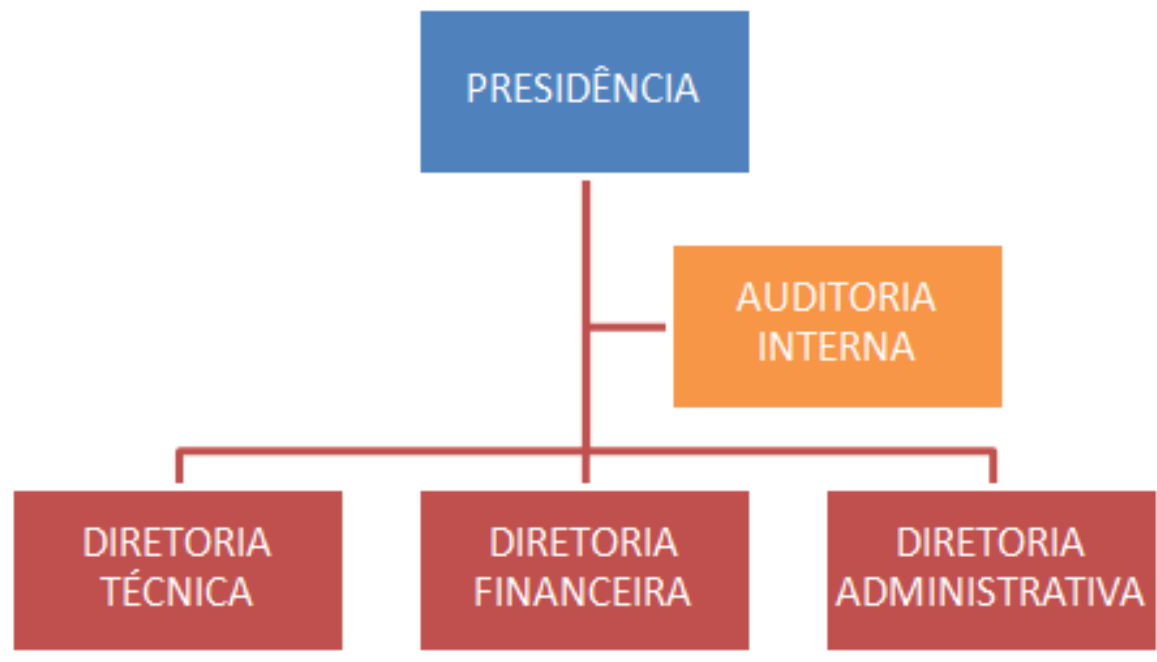

Figura 2 - Estrutura Organizacional com Auditoria Interna Fonte: (ALMEIDA, 2003)

Para Franco e Marra (2011), “o auditor tem uma função social de relevância, em face de sua atuação na defesa de interesses coletivos e como defensor de equidade e justiça, na apuração de corretas prestações de contas. Daí a necessidade de conquistar confiança e respeitabilidade, que deve resguardar e manter, a qualquer preço" (apud CREPALDI; BIANCHI, 2015).

A Constituição Federal, no seu artigo 70, tipifica os tipos de auditoria que o sistema de controle interno de cada Poder deve realizar. Elas são: auditoria contábil, financeira, orçamentária, operacional e patrimonial, e devem observar quanto à legitimidade, legalidade e economicidade.

Franzoni (2004) considera ainda que a auditoria em órgãos públicos é a "avaliação dos controles da Administração Pública a fim de proteger os ativos das organizações e promover a eficiência e eficácia nas operações que permitam tomadas de decisão acertadas em conformidade com a Lei de Responsabilidade Fiscal". 
3.5 Apontamentos de melhoria do processo de Controle e Auditoria Interna

Apesar de todas as medidas levantadas pela Constituição Federal e pela Lei de Responsabilidade Fiscal, ainda ocorrem situações de desvio, má administração de recursos públicos e corrupção.

Como já citado, a auditoria é o ápice do controle, e por isso, a primeira coisa a fazer para garantir que o sistema funcione é avaliar o próprio sistema de controle. Alves (2005?), observa que "[...] todo o enfoque e a natureza da auditoria a ser efetuada dependerão deste confiança no controle interno."

O primeiro passo é o levantamento de sugestões para eliminar qualquer deficiência possível, certificando a credibilidade e confiabilidade do controle interno. Um sistema de controle interno confiável dá maior certeza ao auditor de que as documentações e dados analisados são precisos e verídicos, o que faz o relatório de auditoria seja eficiente na aplicação das ações corretivas (ALVES; REIS, 2005).

Quando a auditoria e controladoria interna funcionam com perfeição, o impacto para o controle social é extremamente positivo, pois as informações levantadas são acuradas e precisas o suficiente para apontarem os erros e problemas a serem corrigidos com mais celeridade do que se realizados pelo controle externo.
Um segundo ponto é promover uma cultura de conscientização e de comprometimento dos agentes públicos da prestação de contas e da responsabilidade de suas ações, pois eles são o elo fundamental entre os órgãos centrais de controle e a Administração Pública como instituição. Gomes (1999, p.34) diz que “[...] o controle do comportamento individual pode ser alcançado não só por técnicas quantitativas, mas pela motivação, participação e formulação de objetivos" (apud SILVA, 2002).

Kanaane at all (2010) pontua que mesmo que o servidor tenha um pensar estratégico ainda há entraves e dificuldades que impedem o serviço público de ter processos flexíveis e versáteis, e que trabalhar o conceito de programa de qualidade no serviço público auxiliaria sua desburocratização, e os servidores conseguiriam potencializar seu trabalho.

E por último, os relatórios de auditoria devem tem uma linguagem clara, precisa, direta e coerente, de forma que não só o seu acesso, mas o seu entendimento seja disponível a todos, mesmo a um cidadão leigo nos conceitos de contabilidade e finanças. (ALVES; REIS, 2005). A formalidade dos relatórios e a pouca divulgação deles à população ainda são empecilhos para um maior controle social.

Matias-Pereira (2010) assinala que “Uma aproximação à comunidade, decorrente 
da consecução responsável de um amplo processo de descentralização administrativa, pode ser a chave para introduzir as mudanças necessárias no modelo atual. É necessário, no entanto, estar pronto para aproximar o governo da comunidade para mobilizar as energias sociais que estão nela presentes em seu favor [...]".

Apesar de na esfera federal se praticar a mobilização e visibilidade sobre o papel da auditoria e controladoria na prestação de contas ao cidadão, e já se disponibilizar ferramentas para o controle social, na esfera municipal, com exceção de algumas capitais, isso ainda é um desafio imenso a ser enfrentado. Os municípios, como menor esfera de governo, são os mais próximos dos cidadãos e, portanto são os que devem praticar uma maior interlocução com os mesmo.

\section{CONSIDERAÇÕES FINAIS}

A Lei de Responsabilidade Fiscal e o conceito de transparência na gestão pública fortalecem a participação do cidadão, imprimem a ele o seu papel como cliente em cobrar um bom retorno do seu recurso aplicado na máquina pública, e com um maior controle social também coíbe a fraude, o erro, a corrupção e a má administração.

A consciência da sociedade brasileira de que a transparência dos atos públicos é um direito de todo cidadão vem fomentando o crescimento da prestação de contas quanto à aplicação dos recursos públicos, que é alcançada por meio da controladoria e auditoria das contas públicas e dos atos públicos.

A autoria interna, com o auxílio da contabilidade e do controle interno, tem objetivo de minimizar a probabilidade de erros intencionais ou não da administração pública, garantindo uma gestão eficaz do Estado, em busca da finalidade do interesse público.

O controle e auditoria interna agem de forma a evitar a prática de ações indevidas das organizações públicas, corrigindo-as internamente, evitando o desgaste da organização com o controle externo, dando agilidade aos atos e processos e evitando o excesso de trabalho dos órgãos de auditoria externa, que ficam livres para se encarregarem de casos mais graves.

De tal forma, o controle e a auditoria não devem ser encarados como um custo à administração, mas como um investimento, como forma de garantir a otimização dos recursos, prevenir e eliminar as fraudes, abusos, desperdícios, e colaborando para a supremacia e indisponibilidade do interesse público.

São, portanto, indispensáveis, pois têm papel vital na garantia de melhor aprimoramento e aperfeiçoamento dos atos administrativos, na publicidade e 
transparência dos mesmos, fortalecendo a democracia pelo controle social.

O combate a corrupção, a transparência, o monitoramento de políticas públicas, a orientação aos servidores públicos e a luta contra a má gestão da res publica passa primeiramente pelo trabalho de controlar e auditar as ações governamentais, portanto, essa prática deve ser executada com plenitude e eficiência nas esferas municipais que são a base da administração pública, assim o cidadão conseguirá efetivamente cumprir o seu papel de controlador social e a democracia se fortalecerá.

\section{REFERÊNCIAS}

ALMEIDA, Marcelo Cavalcanti. Auditoria: Um Curso Moderno e Completo. 6 ed. São Paulo: Atlas, 2003.

ALVES, Ana Lilian Zucareli Sousa; REIS, Jorge Augusto Gonçalves dos. Auditoria Interna no setor público. IX Encontro Latino Americano de Iniciação Científica e $\mathbf{V}$ Encontro Latino Americano de PósGraduação, São José dos Campos/SP, 2005. Disponível em:

<biblioteca.univap.br/dados/INIC/cd/inic/IC6 \%20anais/IC6-63.PDF>. Acesso em: 14 set. 2016.

\section{ASSOCIAÇÃO BRASILEIRA DE} NORMAS TÉCNICAS. NBR 10520: informação e documentação: citações em documentos: apresentação. Rio de Janeiro: 2002.

\section{BRASIL. Casa Civil. Constituição Federal} de 1988. Brasília: Casa Civil, 2016.

Disponível em:

<http://www.planalto.gov.br/ccivil_03/constit uicao/constituicaocompilado.htm >. Acesso em: 15 set. 2016. Casa Civil. Lei Complementar $\mathbf{n}^{\mathbf{0}}$ 101. Brasília: Casa Civil, 2000. Disponível em: <

http://www.planalto.gov.br/ccivil_03/leis/LC P/Lcp101.htm>. Acesso em: 18 set. 2016.

Casa Civil. Decreto-Lei no 200.

Brasília: Casa Civil, 1967. Disponível em: < http://www.planalto.gov.br/ccivil_03/decretolei/Del0200.htm>. Acesso em: 17 set. 2016.

CREPALDI, Michelle Rossini; BIANCHI, Vinicius Rafael. A importância da auditoria interna. Comunicação \& Mercado, UniGran, Dourados, v. 4, n. 10, segundo semestre 2015. Disponível em:

<http://www.unigran.br/mercado/paginas/arti gos10.php>. Acesso em: 01 fev. 2017.

DOMINGOS, Parra Filho; João Almeida Santos. Metodologia científica. 5. ed. São Paulo: Futura, 2002.

FRANSOZI, Marise Gomes. Auditoria em órgãos públicos. Rio de Janeiro:

Universidade de Cândido Mendes - Tijuca, set. 2004. Disponível em: <

http://www.avm.edu.br/novo_site2/monos_ap resentadas.asp? mostrar $=1 \&$ agree $=0$ on $\&$ tipo $=p$ ospresencial>. Acesso em: 25 set. 2016.

GIACOMONI, James. O Orçamento

Público. 15. ed. rev. e ampl. São Paulo: Atlas, 2010.

KANAANE, Roberto; FIEL FILHO, Alécio; FERREIRA, Maria das Graças. Gestão pública: planejamento, processos, sistemas de informação e pessoas. 1. ed. São Paulo: Atlas, 2010.

LAKATOS, Eva Maria; MARCONI, Marina de Andrade. Fundamentos de metodologia científica. 5. ed. São Paulo: Atlas, 2003.

MATIAS-PEREIRA, José. Finanças

Públicas: foco na política fiscal, no planejamento e orçamento público. 6. ed. rev. e atual. São Paulo: Atlas, 2012. 
MENDES, Roselaine da Cruz. Contabilidade Pública. De acordo com as novas Normas Brasileiras de contabilidade aplicadas ao setor público e a Lei de Responsabilidade Fiscal. São Paulo: Atlas, 2011.

MICHEL, André Luiz Silveira. Auditoria governamental: do controle interno à auditoria. [2014?]. Disponível em: $<$ http://andreluizsilveiramichel.jusbrasil.com. br/artigos/117351088/auditoriagovernamental-do-controle-interno-aauditoria>. Acesso em: 14 set. 2016.

CFC. NBT T 11 - Normas de Auditoria Independente das Demonstrações

Contábeis. Brasília: Conselho Federal de Contabilidade, 1997. Disponível em: <http://www.contas.cnt.br/doc/NBCT11.pdf >. Acesso em: 01 fev. 2017.
SCATOLINO, Gustavo; TRINDADE, João. Manual de Direito Administrativo. 3.ed. rev. e ampl. Salvador: Juspodivm, 2015.

SILVA, Pedro Gabril Kenne da. O papel do controle interno na administração pública.

Revista ConTexto, Porto Alegre, v. 2, n. 2, primeiro semestre 2002. Disponível em: $<$ http://www.seer.ufrgs.br/index.php/ConText o/article/view/11555>. Acesso em: 14 set. 2016. 